\title{
G8 nations must end "creative accounting" on foreign aid
}

Published at www.cmaj.ca on Oct. 27

$\mathrm{D}$ uring tough economic times, countries tend to look inward. Politicians focus on creating jobs for their unemployed - and unhappy - constituents. "Buy at home" sentiments begin to surface. But rich countries should not use an economic crisis as a reason to renege on commitments to help people in poorer nations - who have been hit the hardest and daily face inadequate access to clean drinking water, food, sanitation and basic health services - according to Nicci Stein, executive director of the Interagency Coalition on AIDS and Development.

"The impact of the financial crisis is severe and is not going to go away soon," Stein told delegates to an Oct. 26 session on social responsibility and health at the 16th Canadian Conference on International Health in Ottawa, Ontario.

The global financial crisis may have devastated the retirement portfolios of many people in Western nations, but some experts on international health and development claim it is the world's poor who have suffered the most. According to the Food and Agriculture Organization of the United Nations, the ongoing financial problems in many parts of the world have resulted in higher food prices, which have pushed the ranks of the chronically hungry to more than one billion.

In hopes of putting the needs of the poor in the minds of the powerful, a large coalition of Canadian civil society organizations are calling on Canada to add poverty eradication to the agenda of the G8 summit to be held in Huntsville, Ontario, in June 2010.

Stein, who is a member of the 2010 Canadian G8 Civil Society Coordinating Committee coalition, presented an "Agenda for Global Development" during her session (www.icad-cisd.com /content/pdf/CivilSocietyParticipation /G8-Platform-civil-society-EN.pdf).

\section{Time to Act!}

involved now by signing on to the tform at overtyhistory.ca

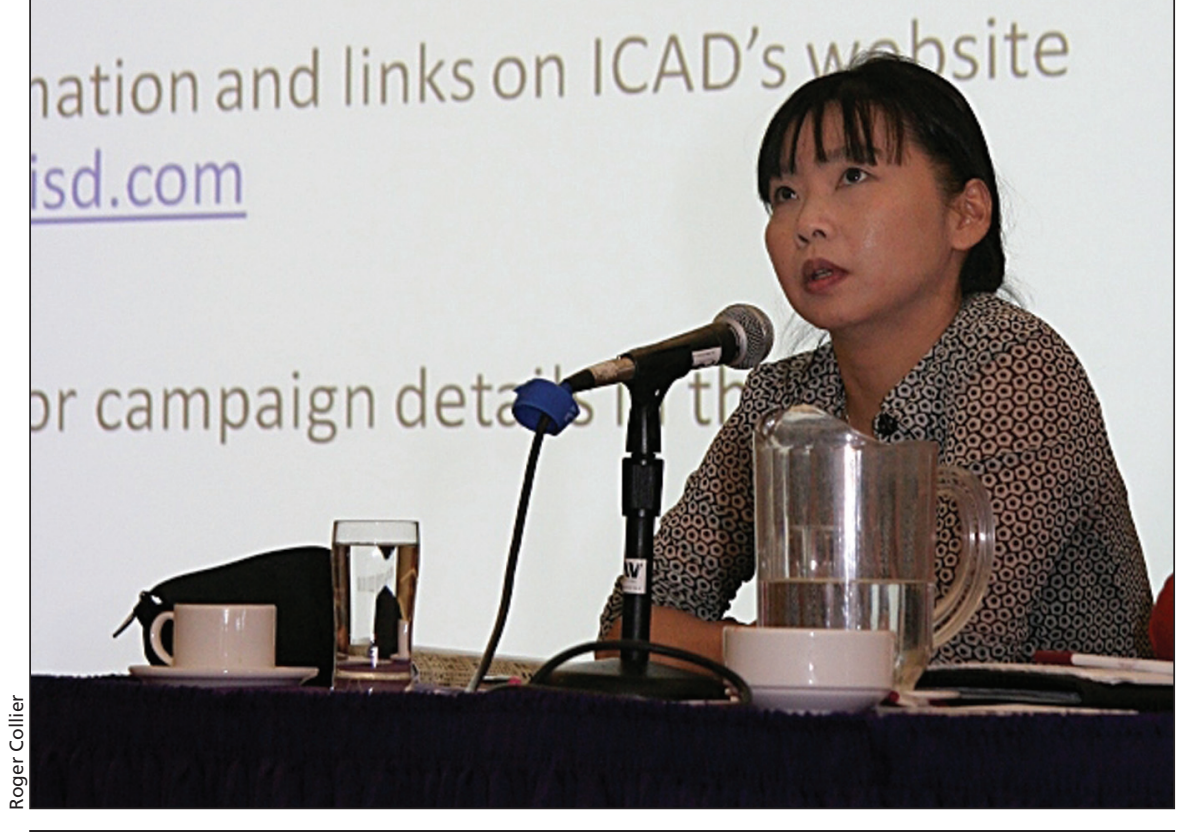

It could be argued that rich nations contribute to "global poverty and ill-health" and therefore have a moral obligation to help poorer nations, according to Ryoa Chung, a professor of philosophy at the Université de Montréal in Montreal, Quebec.

The document states that G8 leaders are at risk of defaulting on past commitments to poorer nations. These include commitments to invest $\$ 60$ billion to fight HIV/AIDS and other infectious diseases; to invest $\$ 1.5$ billion in child and maternal health and to invest $\$ 10$ billion in food security and nutrition intervention.

In order to show good faith that they intend to honour these commitments, the report states, G8 leaders need to improve accountability mechanisms and develop concrete plans of action with timetables.

"The G8 countries keep confirming their commitments but don't disclose anything specific," says Stein. "It's about accountability."

But ensuring that governments meet their promises to aid poorer nations is 
no easy task, says Thomas Pogge, a professor of philosophy and international affairs at Yale University in New Haven, Connecticut.

Often, leaders make vague commitments that, with a little creativity, they can later claim to have met without actually doing much, he says. A commitment to invest millions to improve health care in an African nation, for example, might be "fulfilled" by paying consultants to visit the country, stay in a five-star hotel and later write a report.

"It's all creative accounting," adds Pogge. "This is a huge problem."

Despite the challenges, it could be argued that richer nations have a moral obligation to help poorer nations, according to Ryoa Chung, a professor of philosophy at the Université de Montréal in Quebec. During her presentation to delegates, Chung said rich governments enjoy a "crushing advantage" in power and tend to look out for their own interests, which contributes to "global poverty and ill-health."

Chung added that people in richer nations therefore have a duty to change the institutions contributing to global harm or to compensate those who are being harmed. — Roger Collier, CMAJ

DOI:10.1503/cmaj.109-3090 